\title{
Understanding the Order of Engineering Design Research
}

I. Horváth

Engineering design research manifests as a platform for exploration, description, arrangement, rationalization, and application of design knowledge. What we can see when we are looking at the research into engineering design is an almost chaotically fragmented picture. Is it possible to have a holistic view on the contents and internal relationships of engineering design research? This paper considers teleology, a reflection of a branch of philosophical speculations, as the doctrine of ordering knowledge of engineering design and structuring engineering design research accordingly. Teleology explains that the ultimate reason behind design is to sustain human existence and well being by virtual creation of arlifacts and services for society. To this end, knowledge of engineering research is supposed to be transferred from the platform of scientific/theoretical exploration and comprehension to the platform of technical/pragmatic application. This implies a natural streaming of knowledge of engineering design. In order to make the teleological explanation operational, a framework of reasoning has been constructed by adopting the analogy of the source, channel and sink of a stream. To represent the source, channel and sink categories of engineering design knowledge, the author inaugurated nine categories in the framework. It has been hypothesized that the introduced categories are equally valid for research in engineering design as well as for the knowledge of engineering design. Within each category, research domains and trajectories have been defined. The proposed teleology-based framework lends itself to a better understanding of the disciplinary articulation and intrinsic relationships of engineering design research. It is hoped, among other things, to form a basis for a shared understanding, to make the influence of decisions on research programs more transparent, as well as to facilitate organizing subject materials for various design courses.

Keywords: engineering design research, teleology of engineering design, natural stream of knowledge, research categories, research domains, research trajectories.

\section{Introduction and development of a framework of reasoning}

Engineering design is a creative act, which is understood to be a partially scientific discipline [42]. Design science intends to explore design-related knowledge, look for an understanding of design, search for all forms of truth, and ultimately, explain the act of designing by humans. Eventually, engineering design research is the instrument for exploration, description, arrangement, rationalization, and application of design knowledge. The aim of this paper is to conclude about the contextual arrangement and intrinsic relationships of engineering design research, if these exist at all. The motivation behind this work comes from the observation that engineering design research shows a rather chaotic picture no matter if we look at it from a distance or from inside. On the contrary, the analytical rationality of science, which is especially dominant in natural and abstract sciences, expresses a strong attempt to categorize and arrange all pieces of the explored knowledge [45]. The 'scientific method' attempts to introduce order by structuring the elements of knowledge so as to make proper actions, judgments and evaluations possible. But, can we order engineering design knowledge if the research that produces this knowledge does apparently not obey to order or rule? Or, can we understand engineering design research without a proper comprehension of knowledge of engineering design? These have been the main issues for the research whose recent results are being reported in this paper.

The first assumption of the author has been that engineering design research does obey an order and it can be comprehended by taking the nomothetic relationships of design knowledge into consideration. Nomothetic relation- ships are abstract, general or even universal statements or laws. After Bohm, D., two alternative views can be formed, explicate and implicate [5]. An explicate view is related to observations and allows creating order by phenomenology. Implicate view relates to comprehension and allows creating order by cogitation. In the end, an implicate view creates a holistic order that mutually enfolds all relationships of design knowledge. Adopting an implicate view can definitely help us to discover some nomothetic relationships, but it necessitates an adequate doctrine that enables us to explore any proper relationship. The question is what kind of doctrine can be adopted to obtain any deeper understanding of the content and relationships of design knowledge in an implicate way? In our case, unfortunately, the strategy of inductive reasoning to reach from the facts observed in real life and literature to a hypothesis or a model of reasoning does not work. We have to appeal to a more speculative doctrine, which lends itself to the requested implicate view.

It has been hypothesized that the doctrine of teleology, rather than of mechanism, must be followed toward a better comprehension of the order of engineering design knowledge and research. As a philosophical category, teleology provides explanations of phenomena by the purpose they serve. The doctrine of teleology teaches us about the final reasons of engineering design, and reveals the purpose of the knowledge of engineering design It points at the fact that engineering design is being directed towards an ultimate purpose that manifests in virtual creation of artifacts and services for society [12]. That is, as opposed to mechanism, the teleological view indeed claims that engineering design is determined not only by mechanical causes, but also by an over-all purpose. The doctrine of teleology also attempts to account for the features of engineering design knowledge by appealing to their contribution to functioning and attain- 


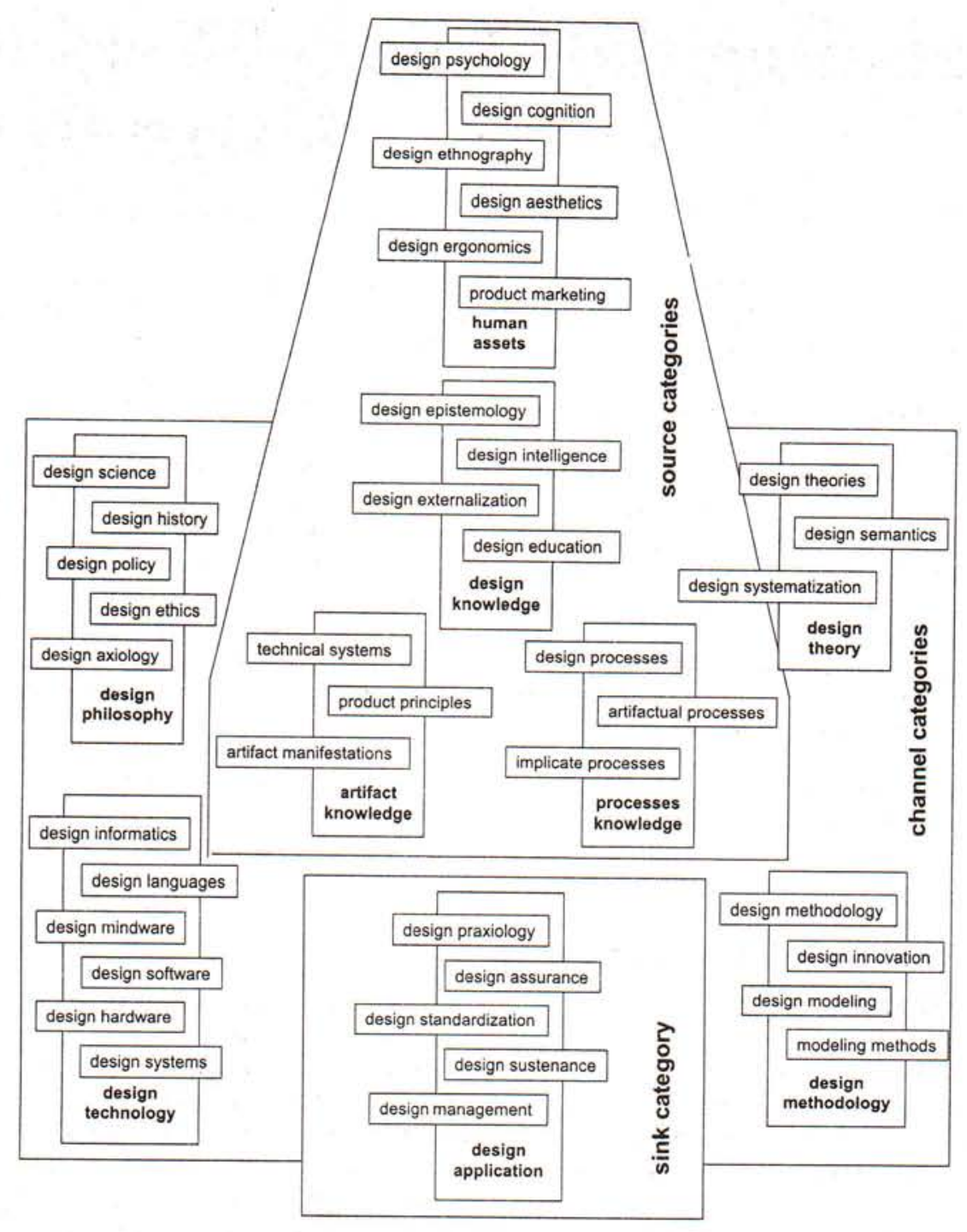

Fig. 1: Conceptual framework of the order in engineering design research

ments of goals. Teleology also says that the ultimate reason does exist without our awareness, recognition or understanding. Neglecting all other implications, we can claim that this ultimate reason is to sustain human existence, to which engineering design contributes through its purpose. Actually, the contribution of engineering design to the fulfillment of societal needs for products and services explains its occurrence and the way of occurrence.

The third assumption has been that, on the one hand, the purpose of engineering design determines the order and the intrinsic relationships of engineering design knowledge. On the other hand, projecting the order of engineering design knowledge to the research of engineering design provides us with the requested implicate view. The hypothesis, supported by some fundamental observations, is that the global discipline of engineering design is naturally rationalized and directed. The knowledge is transferred from the scientific (or theoretical) exploration and comprehension to the technical (or pragmatic) application. Hence, the underpinning idea behind an implicate view can be this natural flow of knowledge through design. The basis of demarcation of the fields of knowledge, as well as in the attentions of research, is the context of purpose. With regards to engineering design research, the categories of fields of interests can be detailed for contents at various levels. Based on these postulates, a framework of reasoning has been constructed that serves four functions: (a) identification of the contextual categories of engineering design research, (b) disintegration of the categories to research domains and making the interactions and dependencies explicit, (c) decomposition of the domains to research trajectories, and (d) breaking down the trajectories to research approaches, whenever this is possible or needed. A research category is a philosophical concept that is based on our thoughts and organizes our experiences accordingly. A research domain is a disciplinary branch of engineering design knowledge and research, representing a particular field of competence or expertise such as history, ergonomics, and management. A research trajectory indicates a stream of operations sharing the same objectives and concepts, which involve modeling a typical example. Finally, a research approach concerns the concrete treatment of specific research issues in engineering design research. 
In order to be able to cast the natural flow of knowledge into a framework of reasoning, the analogy of the source, channel and sink of a stream has been used to define the contextual categories (Fig. 1). As specific to engineering design knowledge, the author inaugurated nine research categories in the framework. The source calegories of engineering design knowledge and research are the categories that endow with the fundamental mental capacity for engineering design. From an epistemic point of view, knowledge pertaining to design may belong to one of four contextual categories: (a) knowledge of human assets, which must be an all-preceding source category, (b) generic knowledge of design, which represents a part of universal knowledge, plus (c) artifact knowledge and (d) process knowledge, which complement each other. The channel categories provide knowledge for establishing couplings between the scientific/theoretical knowledge and pragmatic/technical knowledge categories. The purpose of design philosophy is to improve understanding, of design theory is the proper reasoning with knowledge, of design methodology is the proper utilization of knowledge, and of design technology is the effective application of knowledge. The sink category is concerned with generation of knowledge that is necessary for the ultimate deployment of the whole engineering design knowledge. Design application alone represents this category. Due to space limitations, the discussion of the proposed structure of engineering design knowledge and research must be restricted to the level of design trajectories, as the lowest.

\section{Research trajectories in human assets}

We regard human assets as the whole of the mental and physical capabilities as well as potentials that are owned by a community of human beings and that a business needs to enable its processes to generate new values. Humans relate to engineering design in three forms. They can be (a) scholarly originators of general and specific design knowledge (design philosophers, design scientists, design theoreticians, designers), (b) design problem solvers (design methodologists, engineering designers, product and design system developers), and (c) profiteers from the design deliver- ables (users, consumers, undertakers, students). Within the research category of human assets, six research domains can be identified that decompose to various research trajectories. They are shown in Fig. 2. Design psychology studies the mind and behavior of designers as well as of the people who are affected by design in whichever form [53]. Individual designers, collaborating designers and designer-user mixed groups have been considered [4]. Design cognition research investigates the act or process of knowing, the cognitive mechanisms and mental concepts of knowing, perceiving and conceiving design knowledge, intuitions and hypotheses [49]. It disregards however feelings, emotion, beliefs and volition. It also focuses on the cognitive processes (logical, visual, spatial, and functional thinking) and models of designing [9] and the various techniques of eliciting design knowledge from the design activity on decision, product, and project levels [35].

Stimulated by globalization of industrial production and the need for customized products worldwide, research into design ethnography focuses on distillation of culturally relevant design knowledge, as well as on culture-sensitive design of artifacts [7]. Design aesthetics, the science of sensuous knowledge, studies various aspects of experience beyond the superficial appearance of products, the impression and appreciation of beauty in products, emotional reactions of humans, and the creation of aesthetic values [55]. Design aesthetics involves the study of perception of shape, functions, attributes, and behaviors. It stresses a theoretical argumentation about form, color and other sensory properties. In the domain of design ergonomics, the major research issue is accumulation of knowledge for optimizing the connection between clusters of humans and products/environments [3]. While physical ergonomics concentrates on the investigation of physical human-product interaction with an emphasis on the increase of efficiency, safety, comfort and convenience, informational ergonomics pursues very analogous objectives in mental human-product interaction [37]. High-fidelity multi-aspect modeling of humans based on anthropometrical data, material properties and physical functions, in particular for the investigation of human-product interactions in various user environments, is another main trajectory of research in this domain. Supported by the general theories of marketing, product marketing research covers a subset of fields of interests that specifically belong to marketing of artifacts and to related

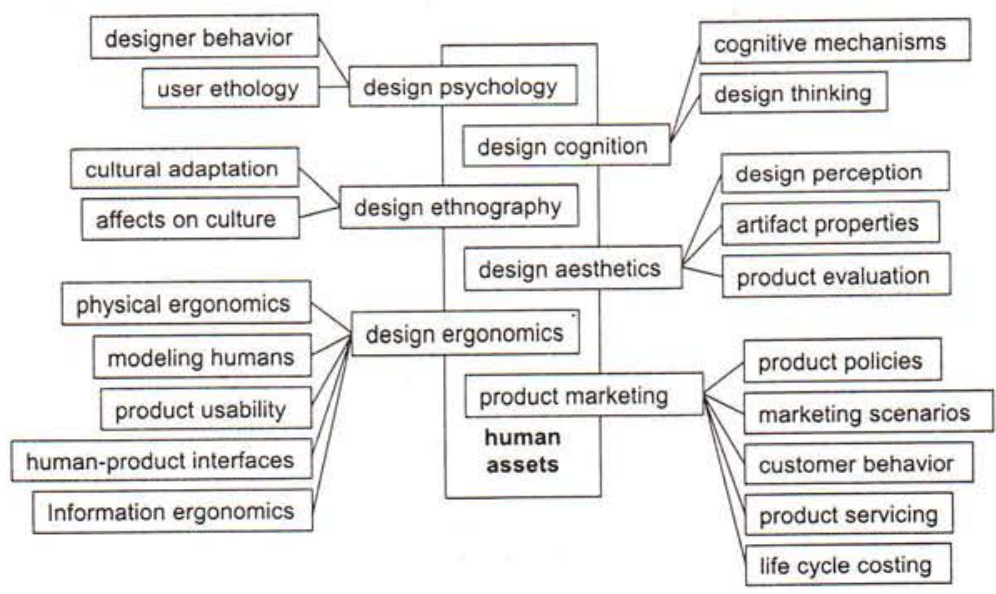

Fig. 2: Research trajectories in human assets 
technical services [47]. The major fields of attention in this research domain include product policies, marketing scenarios and processes, customer behavior, product servicing and life cycle costing. Customer behavior studies have received specific attention especially related to consumer products [28].

\section{Research trajectories in design knowledge}

The structure of research in the contextual category of design knowledge is shown in Fig. 3. By adopting the doctrine of epistemology of scientific knowledge, design epistemology deals with the competing theories of design knowledge with respect to its origins, nature, forms, constituents, structure as well as to its validation and methods [13]. There is a strong coupling to the category of human assets, since human involvement is the only way of acquiring design knowledge from the natural, social and technical sciences, as well as from design practice. Although it was found to be fundamentally empirical in nature, engineering design research has made design knowledge more theoretical by structural reasoning, abstraction and generalization, and logical processing [26]. Contemporary research in this domain has found that, in the most general sense, design knowledge can be synthetic, as acquired by the cognitive senses, and analytic, as derived by mental reasoning. Design intelligence extends the intrinsic forms of human intelligence, that is, linguistic, musical, logical, spatial, kinaesthetic and personal thought processes [17].

The research in the domain of design intelligence investigates the principles and forms of common, plausible and non-deterministic design reasoning and learning, together with the apprehension of specific problem solving capabili- ties, the nature and manifestations of design creativity, as well as the nature of design problems and handling of holism and complexity of design problems [8]. While design thinking investigates the cognitive and intuitive mechanisms, design reasoning considers the rational foundations with the aim of deriving principles for procedural inference [31]. Design reasoning based on formal logic has been considered a means of mechanical realization of design, rather than a means of achieving a creative leap [36]. In the domain of design externalization, research splits into three main trajectories: (a) generating mental images (concepts) and converting them to abstract or concrete schemata, (b) representations applicable to transfer mental images to external representations, and (c) communication of design ideas, information and design knowledge [50]. The research in the domain of design education decomposes to the study of (a) design teaching and learning processes, methods and tools, (b) development and experiencing with various design learning programs, and (c) exercising product design and realization by co-located or dislocated collaborative groups [46]. One of the most important findings of research in the design instruction trajectory is the observation that design is not separative, like science, but integrative, like art and engineering, which has to be characteristic for education in the information age [40].

\section{Research trajectories in knowledge of artifacts}

Knowledge related to artifacts, also named technical systems or products, represents a specific subset of design knowledge. In the context of design, a wealth of complex artifacts appeared during the great industrial revolution and later. Historically the first artifact theories were about mecha-

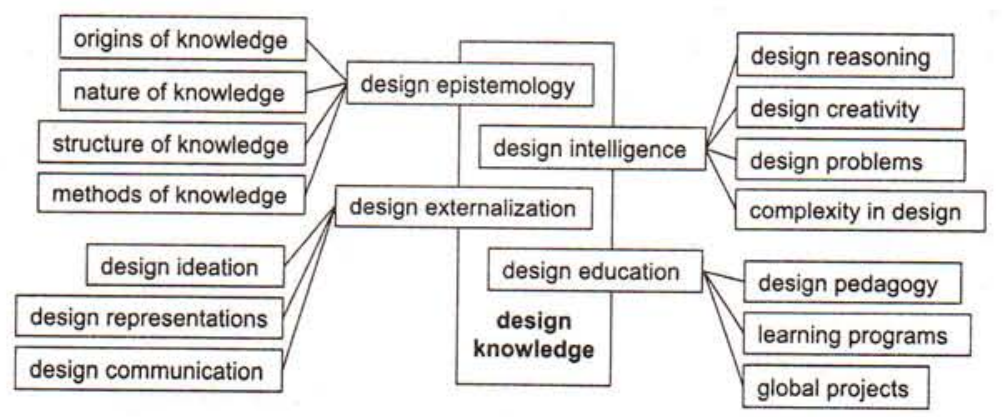

Fig. 3: Research trajectories in design knowledge

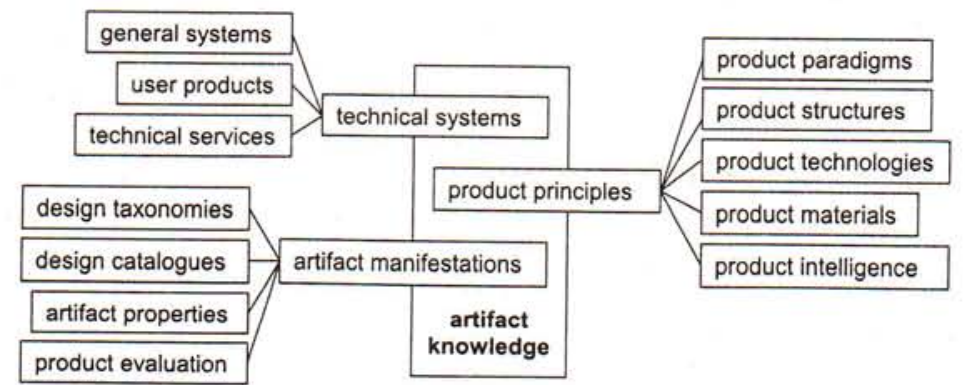

Fig. 4: Research trajectories in artifact knowledge 
nisms rather than about compound machinery or products. Looking back over a long history, the research into artifacts intends to understand the rules, forms and relations of processing substance, energy and information in designs. The author distinguishes three domains of research into the realm of artifacts, specifically the domain of technical systems, product principles and artifact manifestations (Fig. 4). Research recognizes technical systems as goal-implied, synergetic arrangements of organs, and places the emphasis on the laws of transformations, casual changes and optimization of operation [25].

The domain of product principles is populated by the research trajectories of product paradigms [44], structures, technologies, materials and product intelligence [43]. Research in the domain of artifact manifestations is composed of research in the trajectories of design taxonomies, design catalogues, artifact properties and the methods and tools of product evaluations. The aims of research in design taxonomies are (a) to discover general principles for orderly classifications of designs and their relationships, and (b) to classify purposeful artifacts in various classes based on extensional or intentional properties [56]. Design catalogues have been studied as (a) warehouses of artifact related knowledge and (b) means of supporting systematic creativity [57]. Research in product properties is interested in attaining optimal values for influential properties such as weight, complexity, efficiency, reliability, adaptability and crashworthiness.

\section{Research trajectories in knowledge of processes}

There are many aspects to the discussion of design related processes. The main domains of research in this category are (a) design processes, (b) artifactual processes and (c) implicate processes (Fig. 5). Research in the domain of design processes decomposes to the study and modeling of design processes as well as to optimization of the transformations and the use of resources in design processes to improve qualities [11]. The firstly mentioned trajectory of research incorporates explanation, generalization and/or abstraction of observed design processes, and devising theorems, rules and procedures as a set of instructions for solving design problems. Process modeling studies the theoretical formalization of processes, the ways of contextual understanding and information technological modeling of processes [30]. Understanding design processes is the topic for process theory specializing in design [51]. The creative design processes have been found dependent on the subconscious ideas that produce something not known beforehand [21]. Monitoring and protocol study are applied to understand the human ways of designing, processing design information, applying knowledge, collaboration, use of tools and methods, and design communication.

The research domain of artifactual processes spreads over existential, operation, application and service processes of products. These are essentially the constituents of the life cycle of products. The research studies these product-related processes in a holistic way, with the aim of understanding, modeling, simulating and optimization. Implicate processes relate to the realization and exploitation of products. Research in this domain deals with technological, production, sales and reclaiming processes. Technological processes are about manufacturing and assembling parts, and they are studied in order to provide information for designers for technology-oriented decisions in the process of designing artifacts. Production processes are about the realization of products in

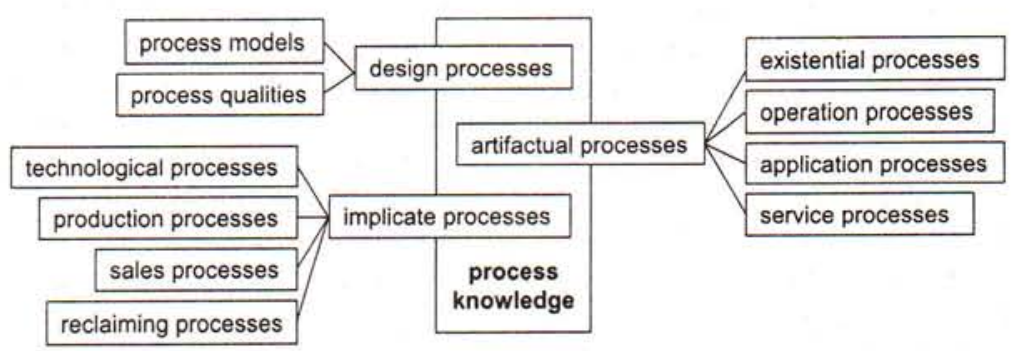

Fig. 5: Research trajectories in design-related process knowledge

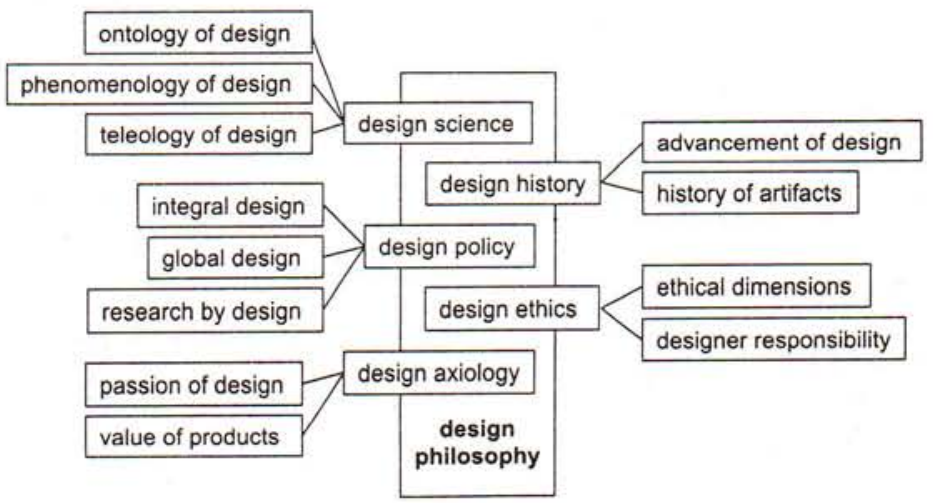

Fig. 6: Research trajectories in design philosophy 
various production environments such as conventional, real time extended and virtual companies.

\section{Research trajectories in design philosophy}

Historically, philosophical inquiry targeted the issues of epistemology, aesthetics and ethics of engineering [14]. Design philosophy is the highest level speculative thinking about (a) the existence and manifestation of design, (b) the role and position of design in society, (c) the historical evolution of design, and (d) the foundational basis of design thinking [61]. Philosophy of design is sometimes equated to a meta-theoretical framework for design theories [34]. The author considers design science, design history, design policy, design ethics and design axiology as current domains of design philosophy research, as shown in Fig. 6. Design science is a scientific study of design activity in its context, and generates a collection of logically arranged knowledge in the realm of design. (In contrast, the science of design is the study of a scientific way of designing). Hubka, V. and Eder, W. E. identified two constituents of design science as concepts of technical information and of design methodology [24]. Willem, R. A. found that there exist two knowledge-level interactions between science and design [59].

Design history research focuses on the chronological development of design knowledge and the subdisciplines, advancement of philosophical and theoretical frameworks (paradigms), and also on political, social, cultural, and economic factors influencing the trends in the development of products and designing [22]. Emerging design policy research concerns the executions of complex research projects, knowledge about planning collaborative design processes and outsourcing strategies for design projects. It usually concerns a high-level overall plan embracing the general design goals and acceptable design procedures. The course of actions and/or applicable methods is selected from alternatives with a view to existing or hypothesized conditions. Research in design ethics studies the ethical dimension in engineering design, including man-made changes to nature, the principles of a product that will be useful for society as well as the rules of designing considering all moral, social, political, cultural and personal aspects. The main issue of research is what rules reflect the norms of the society and should govern the design activities, and what is the ethical sphere of individual responsibility. Design axiology research is developing spontaneously to study the nature and the measures of the technical, economic, moral, social and aesthetic values created by design.

\section{Research trajectories in design theory}

Design theories are dedicated to the organization of engineering design knowledge beyond the level of craftsmanship. The research in the category of design theory decomposes to the domains of design theories, design semantics, and design systematization (Fig. 7). Research in the domain of design theories deals with both global and local theories. Descriptive, prescriptive and formal theories have been identified [15]. Global theories concern both design artifacts and design processes [20]. Hubka, V. and Eder, W. E. specified the content for the theory of technical systems as the total of sub-theories such as property theory, structure theory, transformation (process) theory, conformational theory, life-stage theory, evolution theory, and ecology theory [24]. A global design problem solving theory generally serves as a scientific basis for rationalizing multidisciplinary product development. One of the proposed global theories is general design theory (GDT), which aims at introducing an idealized model for the evolutionary design process [60]. Specific design theories are localized in scope, that is, they are connected to one or several particular problems of engineering design. A local design theory emerges when there is a testable explanation of why the method behaves as it does. Formal local theories are typically based on formalized theorems, rules and structured procedures, and are used in automating solution finding for design subproblems [6]. Research in the trajectory of design mappings focuses on specific problems of design such as (a) converting ideas to a formal specification, (b) mapping requirement structures to functions and functional structures, (c) clarification of functions and functional relationships, (d) grasping the function to form transition, (e) perception of shapes and shape morphing, (f) clarifying relationships of shape and behavior, and (g) study of design evolution.

Research in design semantics targets meanings and intentions in design [1]. Among the goals are (a) understanding the meaning as it relates to design and explicating design intents, (b) exploring design aspects and consideration of them in the design process, (c) contextual understanding of designing and designing in contexts, and (d) axiom-based approaches to design. Design semiotics studies the symbolisms applied in the key functional activities in design and in the related activities. Design axiomatism strives to develop and apply formal reasoning frameworks from a limited number of axioms

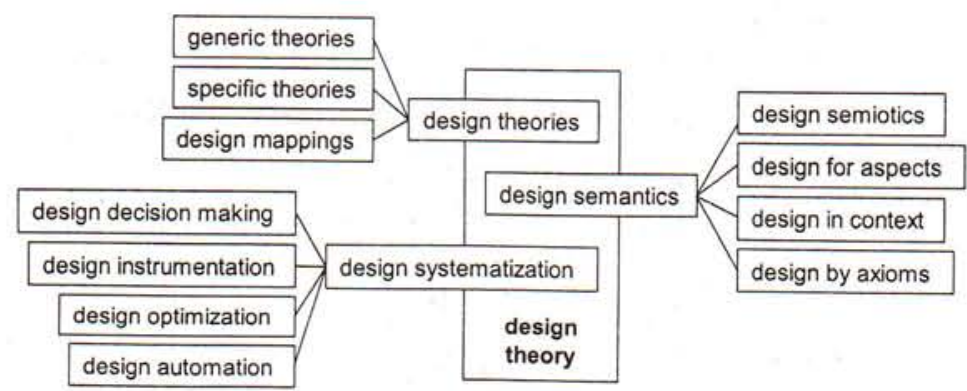

Fig. 7: Research trajectories in design theory 


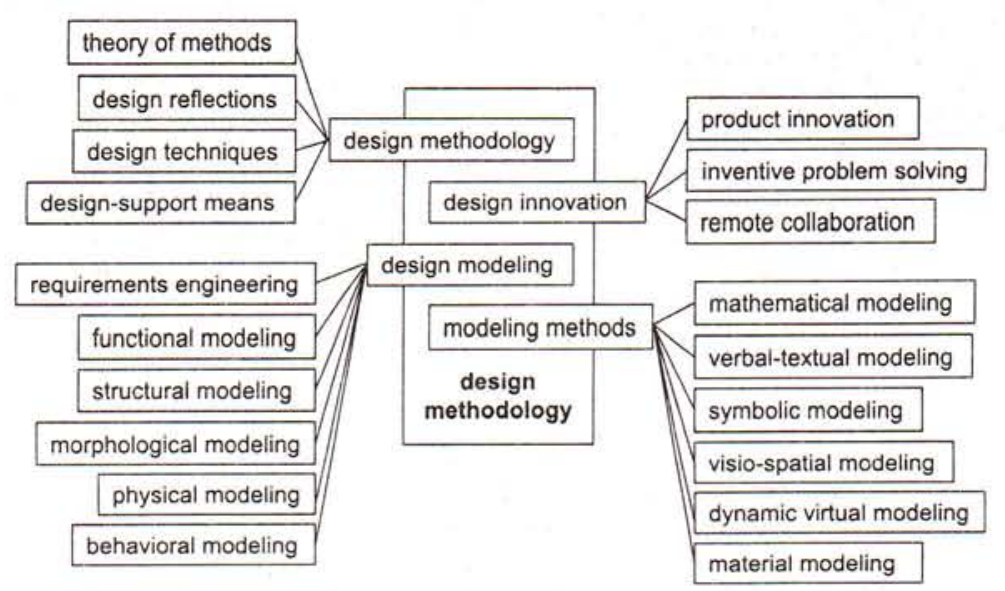

Fig. 8: Research trajectories in design methodology

(self-evident truths), propositions (conjectures) and/or facts. Based on the work of Russel, B., we can conclude that there are no truths par excellence in engineering design, which makes its axiomatic definition logically unsupported [48]. The domain of design systematization incorporates research into (a) design decision-making, (b) design instrumentation, (c) design optimization, and (d) design automation. The research studies individual, team and organizational levels of design decision-making. Design instrumentation studies the dialect of design tools and design processes, humans and tools, and problems and tools. Design optimization research targets both qualitative and quantitative methods of system, structure, shape and parameter optimization. Design automation research, which assumes that engineering design is a computable function, studies computer-based problem solving strategies, methods, heuristics, creativity, learning, and reasoning. Its ultimate aim is formal design inference, automated problem solving, and transplantation of design capabilities.

\section{Research trajectories in design methodology}

Design methodology is the theory of design methods, activities and techniques. Many researchers have proposed a separation between the so-called scientific method and design method [10]. This view is well supported by the vast amount of non-scientific knowledge that is applied in engineering design. The author's understanding is that the category of design methodology research embraces the domains of design methodologies, design innovation, design modeling and modeling methods (Fig. 8). Design methodologies involve the systematic analysis and organization of the rational, experimental and heuristic principles and processes in order to solve design problems. Eekels, J. and Roozenburg, $\mathrm{N}$. F . introduced the notion of design methodics to differentiate the theory of methods from the development and application of methods. Design methods do not attempt to say what design is, or how human designers do what they do, but rather provide tools by which designers can explain and perhaps even replicate certain aspects of design behaviors [27].

Design innovation research creates a scientific basis for rationalizing multidisciplinary product development and fa- cilitates solution finding for design problems. Also studied are the relationships between design innovation strategies and the underlying range of technical choice available to the design team [33]. With the advent of digital computers, a new field of attention has gradually been emerging in design methodology, design modeling. Its objective is to generate mental, cognitive, formal and symbolic models of humans, artifacts, processes and knowledge [2]. It investigates the role of models in externalization, communication and testing of design ideas [62]. Design modeling covers the research trajectories of requirement engineering, functional, structural, morphological, physical, and behavioral modeling of products. Expectations coming from the phases of the life cycle of products are also investigated. The research domain of modeling methods deals with mathematical, verbal-textual, symbolic, visio-spatial, virtual and material methods of representation of humans, artifacts, processes and knowledge, and their integral use in engineering design. Typically, verbal starting points are transformed into initial physical representations supported by visuo-spatial thinking [38].

\section{Research trajectories in design technology}

Science philosopher Ziman, J. said that science in application is technology [63]. Cross, N. asserted that design is more a technological activity than a scientific activity; therefore it has to be seen from the more practical and stable technological model of human action, rather than from a formal scientific theory [10]. According to the author, design technology is the most characteristic channel category that converts the general knowledge of engineering design to explicit product models and representations. With the advent of digital computers, design technology has become one of the most intensively studied research categories of engineering design. Therefore, some 30 years ago, design technology research showed an unexpectedly rapid progress [23]. The involvement of computers in design, pulled by the needs of industry and pushed by the rapidly evolving computer technology, has actually brought about the concept of design technology. The two fundamental problems have been the processing of design knowledge by computers, and the development of design supporting systems. The specific research domains are shown in Fig. 9. 


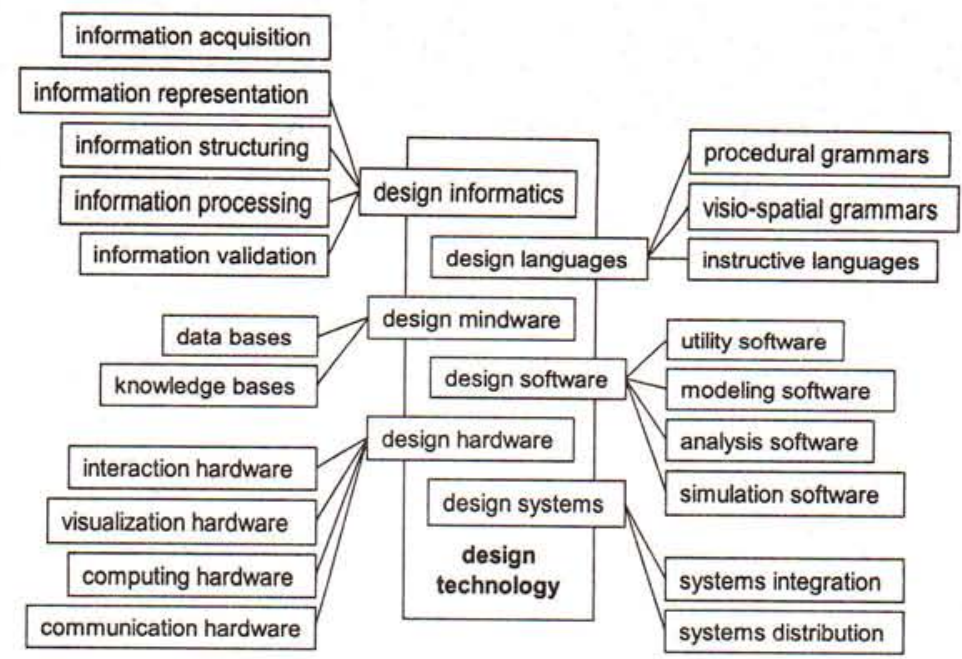

Fig. 9: Research trajectories in design technology

Research in the domain of design informatics aims at studying all non-specific aspects of handling data, information and knowledge related to humans, methods, tools and products. It concerns acquisition, representation, structuring, processing and validation. The premier issue has been processing visual and spatial information, which is enabled by the methods and techniques offered by computer graphics research and image processing [16]. Research in the domain of design languages targets formal product definition languages as well as product description languages of neutral formats. Another research domain, design mindware, deals with the issues of structuring and archiving design data, information and knowledge in design databases in textual, numeric, visual and multi-media forms. Knowledge bases for design relying on conventional representation schemes, taxonomical ontologies, or multimedia representation as well as knowledge asset warehousing are also investigated [41]. The research domain of design software comprises research into the exploration of theories, methods and algorithms for (a) design utilities, (b) graphics-based modeling software, (c) analysis software and (d) simulation software [32].

Facilitating the development of design support systems on the computational side, historically (a) interaction, (b) visualization, (c) computing and (d) communication hardware research formed the four trajectories in design hardware research. Research into graphical hardware grew in parallel with the research of graphical input and output means. In the light of the existing concepts and achievements of all-pur- pose hardware research, the importance of the computing and communication trajectories is fading away. Supporting multi-channel natural communication and true $3 \mathrm{D}$ presentations are in the focus of current hardware research in the interaction and visualization trajectories. Design systems research aims at the integration of various design tools into a single holistic system that is able to support all actions of designers. From the concept of multifunctional systems, through model-based integrated systems, research has entered the realm of collaborative virtual product development environments. As a basis for of integration several concepts such as centralized databases, associative models, multiple feature views, shared product models, remote collaboration management and tele-presence have been tested [39].

\section{Research trajectories in design application}

Design application means the utilization of generic design knowledge and specific design information in designing products and product related services. Design application research, as the only sink category, studies the ways of deploying artifact and process knowledge as well as design theories, methodologies and technologies in solving concrete design problems. The related research domains and trajectories are shown in Fig. 10. Coined by Kotarbinsky, T., design praxiology research has a broader and a narrower interpretation, and is still a matter of debate [29]. In its broader interpretation it

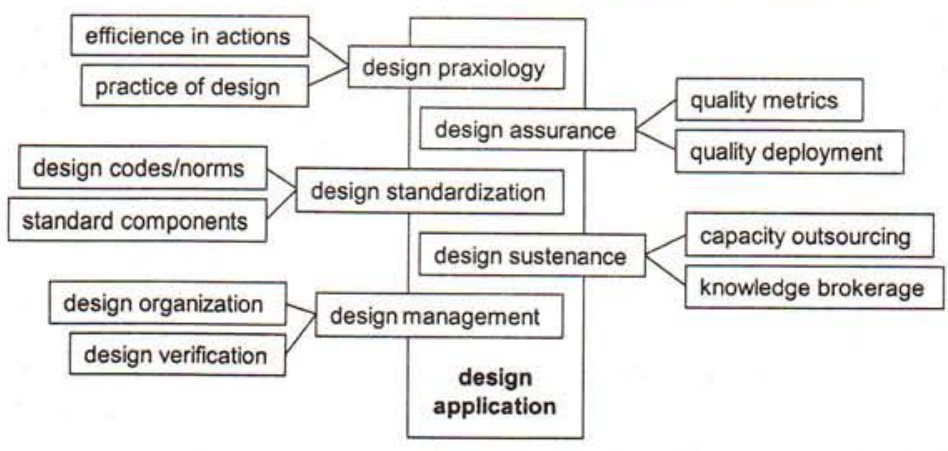

Fig. 10: Research trajectories in design application 
goes toward the theory of efficient design action, and in its narrower meaning it is focused on design problem solving and organization. Design assurance research concerns both the quality of design actions and the quality of deliverables. One trajectory of research creates norms and measures of design quality, and the other is involved in the deployment of quality [52].

Design standardization research targets the increase of efficiency and quality of design by investigating the principles of standardization, stating the requirements and characteristics of artifacts, processes and methods, and generating codes and norms with a pronounced relationship to design technology [54]. Receiving amplified interest in the last decade, research in design sustenance deals with the capacity management issues of design projects and looks for strategies and principles for design outsourcing, knowledge brokerage and conducting collaborative product development [19]. Finally, research in the domain of design management investigates the methods of low-level organization of designing [18], exploitation of design tools for particular products, and verification and reviews of evolving design [58]. Design management research involves the study of: (a) design office management, (b) design project management, (c) organization of design management, (d) management training for designers, and (e) design training for managers.

\section{Conceived Influences of the framework of reasoning}

Driven by practical or utilitarian considerations, one can obviously ask: What benefit can we draw from all these? For design scientists, researchers and educators it is most probably not difficult to see the relevance or usefulness of this (or other purposeful) reasoning model, but they might meditate about the best forms of utilization. Most probably, designers and design managers will formulate their question even more profanely: Can we design better now? All these questions in the context of utility are justified. Each theory must be measured in terms of its usefulness. Implicitly, this is the message of the reasoning model itself. However, more often than not, the usefulness of a theory or a framework of reasoning appears indirectly, rather than directly. And the indirect influence might be much greater than any direct influence. Presumably, this is true in our situation. In any case, influence and especially usefulness needs further evidence in order to gain acceptance as sensible. Here we mention four fields where the usefulness of the teleological framework of reasoning can be proven: (a) conceptual framework of development of ontologies for engineering design research, (b) structuring engineering design knowledge, (c) strategic and tactical organization of engineering design research, and (d) facilitation of knowledge intensiveness in product development.

Design ontologies are the specifications of conceptualization of knowledge related to a particular field of interest. Actually, the presented teleological reasoning model defines and arranges the highest-level concepts (categories, domains and trajectories). It introduces a hierarchical structure that is a widely accepted form of arranging knowledge. Thus the teleological reasoning model lends itself to the highest-level conceptual framework of ontology development for engineering design research. It provides us with a set of concepts and the hierarchical relationships of the concepts, reflects a shared understanding and commitment, and serves as a common vocabulary of design scientists and practitioners. Lower level (specific) ontologies of engineering design research can be derived from the teleological reasoning model in a consistent and transparent way. In this way the high level systematization goes into human and software agents supporting design information and knowledge mining, retrieval, processing, archiving and reasoning.

The teleological reasoning model is able to support a systematic structuring of engineering design knowledge. The order it introduces is an explicate order for engineering design research and an implicate order for engineering design knowledge. The notion of implicate order can be easily understood by analogy with image generation in TV sets. The transmitted electronic signals should be in an arrangement and form that result in the correct screen picture. The contribution of the proposed reasoning model to the understanding of engineering design knowledge is of this kind. Although further research is needed, the conceptual framework can be used to arrange the disciplinary knowledge of engineering design and to facilitate, among other things, knowledge asset management, ontology development, and education material development.

In the course of time, some specific topics and approaches of engineering design research incidentally receive greater emphasis at the expense of other issues. Everywhere in the world, design research grants are awarded mainly by particular local interests, very rarely with concern about the development of the science of designing as a whole. Granters control the publication possibilities depending on their commercial objectives. The orientation of scientific development is influenced more by the editors-in-chiefs of publishing houses than by an unprejudiced understanding of useful trends and a comprehensive view on the orientation of scientific development. The conceptual framework gives a kind of topography of engineering design research, which can be utilized in the strategic and tactical financing and organization of engineering design research. The integral view that it provides on engineering design research can make the articulation of research on the level of trajectories and approaches transparent for the decision makers, and indicates the emergence of a new paradigm when harmony with the framework tends to cease and adaptation becomes a necessity.

Understanding the order, exploration mechanisms and knowledge transfer of engineering design research has become indispensable in an age when technological progress is accelerating almost unconstrained. The teleological reasoning model says that the scientific (or theoretical) knowledge explored by research in engineering design must be transferred to technical (or pragmatic) application. Shortening the time of knowledge transfer from research to practice and coping with the knowledge explosion are generally recognized issues. The author believes that a better understanding of the relationships between the knowledge produced by the various branches of research enables us to better cope with the pragmatic issues. What is waiting for further research is the study of those mechanisms that facilitate the achievement of knowledge intensiveness in product development based on a short-term conversion of the results of engineering design research. 


\section{References}

[1] Akman, V., Surav, M.: Steps Toward Formalizing Context. AI Magazine, 1996, Vol. 17, No. 3, p. 55-72.

[2] Anderl, R.: Trends in Product Modelling. In: Proceedings of the International Conference on Engineering Design ICED 97, ed. by Riitahuhta, Tampere, FL, Vol. 1, 1997, p. 113-120.

[3] Andersson, E. R.: A Systems Approach to Product Design and Development - An Ergonomic Perspective. International Journal of Industrial Ergonomics, Vol. 6, 1989, p. 1-8.

[4] Arnabile, T. M.: The Social Psychology of Creativity. New York: Springer-Verlag, 1983.

[5] Bohm, D.: Wholeness and the Implicate Order. London: Routledge Classics, 1980.

[6] Braha, D., Maimon, O.: A Mathematical Theory of Design: Foundations, Algorithms and Applications. Boston: Kluwer Academic Publisher, 1998.

[7] Bucciarelli, L. L.: An Ethnographic Perspective on Engineering Design. Design Studies, Vol. 9, No. 3, 1988, p. 159-168.

[8] Chandrasekaran, B.: A Framework for Design Problem Solving. Research in Engineering Design, Vol. 1, 1989, p. $75-86$.

[9] Christiaans, H. C., Dorst, K. H.: Cognitive Models in Industrial Design Engineering: A Protocol Study. In: Proceedings of 1992 ASME Design Theory and Methodology Conference, Vol. 42, 1992, p. 131-137.

[10] Cross, N., Naughton, J., Walker, D.: Design Method and Scientific Method. Design Studies, Vol. 2, No. 4, 1981, p. 195-201.

[11] Ertas, A., Jones, J. C.: Engineering Design Process. New York: John Wiley \& Sons.

12] Dilnot, C.: 1982, Design as a Socially Significant Activity: An Introduction. Design Studies, Vol. 3, No. 3, 1995, p. 139-146.

[13] Dimarogonas, A. D.: The Origins of Engineering Design. In: Proceedings of ASME Design Engineering Technical Conferences, Albuquerque, NM, ASME, New York, Vol. 63, 1993, p. 1-18.

[14] Dimarogonas, A. D.: Philosophical Issues in Engineering Design. Journal of Integrated Design and Process Science, Vol. 1, No. 1, 1997, p. 54-75.

[15] Finger, S., Dixon, J. R.: A Review of Research in Mechanical Engineering. Research in Engineering Design, Part 1, Vol. 1, No. 1, 1989, p. 51-68, Part 2, Vol. 1, No. 2, 1989, p. 121-137.

[16] Foley, J. D., van Dam, A., Feiner, S. K., Hughes, J. F.: Computer Graphics: Principles and Practice. Reading, MA: Addison-Wesley, 1990.

[17] Gardner, H.: Frames of Mind: The Theory of Multiple Intelligences. London: Heinemann Publisher, 1983.

[18] Gorb, P.: Design Management. London: Architecture Design and Technology Press, 1990.

[19] Hardagon, A. B.: Technology Brokering and Innovation in a Product Development Firm. Administrative Science, Vol. 42, 1997, p. 716-734.

[20] Henderson, M. R., Taylor, L. E.: A Meta-Model for Mechanical Products Based Upon the Mechanical Design
Process. Research in Engineering Design, Vol. 5, 1993, p. 140-160.

[21] Hertz, K.: A Coherent Description of the Process of Design. Design Studies, Vol. 13, No. 4, 1992, p. 393-410.

[22] Hill, D. R.: A History of Engineering in Classical and Medieval Times. LaSalle: Open Court, Il, 1984.

[23] Horváth, I.: Shifting Paradigms of Computer Aided Design. Delft: Delft University Press, 1998, p. 1-36.

[24] Hubka, V., Eder, W. E.: A Scientific Approach to Engineering Design. Design Studies, Vol. 8, No. 3, 1987, p. 123-137.

[25] Hubka, V., Eder, W. E.: Theory of Technical Systems: A Total Concept Theory for Engineering Design. Berlin: Springer-Verlag, 1988.

[26] Hubka, V., Eder, W.: Design Knowledge: Theory in Support of Practice. Journal of Engineering Design, Vol. 1, 1990, p. $97-108$.

[27] Jones, J. C.: Design Methods: Seeds of Human Futures. New York: Wiley Interscience, 1980.

[28] Kassarjian, H. H.: Personality and Consumer Behavior: A Review. Journal of Marketing Research, Vol. 8, 1971, p. 409-418.

[29] Kotarbinsky, T.: Praxiology: An Introduction to the Science of Efficient Action. London: Pergamon Press, 1965.

[30] Kusiak, A., Wang, J.: Efficient Organization of Design Activities. International Journal of Production Research, Vol. 31, No. 4, 1993, p. 753-769.

[31] Lawson, B.: How Designers Think: The Design Process Demystified. London: Architectural Press, 1980.

[32] Lee, K.: Principles of CAD/CAM/CAE Systems. Reading, MA: Addison-Wesley, 1999.

[33] Little, S. E.: Incremental and Systemic Innovation Strategies: Reflections of Technical Choice. Design Studies, Vol. 8, No. 1, 1997, p. 41-54.

[34] Love, T.: Philosophy of Design: A Meta-Theoretical Structure for Design Theory. Design Studies, Vol. 21, No. 3, 2000, p. 293-313.

[35] Magee, K.: The Elicitation of Knowledge from Designers. Design Studies, Vol. 8, No. 2, 1987, p. 62-69.

[36] March, L.: The Logic of Design. In Developments in Design Methodology, ed. by Cross, N., New York: Wiley, 1984, p. 265-276.

[37] McClelland, I.: Product Assessment and User Trials. In Evaluation of Human Work, ed. by Wilson, J. R., Corlett, E. N., London: Taylor and Francis Publisher, 1995.

[38] Muller, W.: Design Discipline and the Significance of Visuo-Spatial Thinking. Design Studies, Vol. 10, No. 1, 1989, p. $12-23$.

[39] Navon, J., Stotts, D., Furuta, R.: Collaborative Hyper Documents and Prototyping Groupware. Computers in Industry, Vol. 29, No. 1, 1996, p. 91-104.

[40] Owen, C. L.: Design Education in the Information Age. Design Studies, Vol. 11, No. 4, 1990, p. 202-206.

[41] Owen, R., Horváth, I.: Towards Product-related Knowledge Asset Warehousing in Enterprises. In: Proceedings of the Fourth International Symposium on Tools and Methods of Competitive Engineering, ed. by Horváth, I., Li, P., Vergeest, J. S. M., Wuhan: HUST Press, 2002, p. $155-170$. 
[42] Pahl, G., Beitz, W.: Engineering Design: A Systematic Approach. New York: Springer-Verlag, 1988.

[43] Paynter, H. M.: Analysis and Design of Engineering System. Cambridge, MA: MIT Press, 1961.

[44] Petroski, H.: Design Paradigms. Cambridge: Cambridge University Press, 1994.

[45] Popper, K.: Conjectures and Refutations. London: Routledge and Kegan Paul, 1963.

[46] Portillo, M. B., Dohr, J. H.: Design Education: On the Road Towards Thought Development. Design Studies, Vol. 10, No. 2, 1989, p. 96-102.

[47] Raaij, van, W. F., Antonides, G., Oppendijk van Veen, W. M., Schoormans, J.: Product and Consument. Utrecht: Lemma BV, 1999, (in Dutch).

[48] Russel, B.: The Problems of Philosophy. Oxford: Oxford University Press, 1912.

[49] Schön, D. A.: The Reflective Practitioner. New York: Basic Books, 1983.

[50] Smith, R. P., Morrow, J. A.: Product Development Process Modeling. Design Studies, Vol. 20, No. 3, 1999, p. 237-261.

[51] Sohlenius, G.: Concurrent Engineering. Annals of CIRP, Vol. 41, No. 2, 1992, p. 645-655.

[52] Taguchi, G.: Introduction to Quality Engineering: Designing Quality into Products and Processes. Tokyo: Asian Productivity Organization, 1986.

[53] Thomas, J. C., Carroll, J. M.: The Psychological Study of Design. Design Studies, Vol. 1, No. 1, 1979, p. 5-11.

[54] Toms, P.: Standards and the Design Process. Design Studies, Vol. 9, No. 2, 1988, p. 115-122.
[55] Tovey, M. J.: Styling and Design: Intuition and Analysis in Industrial Design. Design Studies, Vol. 18, 1997, p. 15-31.

[56] Ullman, D. G.: A Taxonomy for Mechanical Design. Research in Engineering Design, Vol. 3, 1992, p. 179-189.

[57] VDI, Richtlinie-2222, Blatt 2: Erstellung und Anwandung von Konstruktionskatalogen, Berlin: VDI-Verlag, 1977.

[58] Warfield, J. N.: A Science of Generic Design: Managing Complexity Through Systems Design. Ames: Iowa State University Press, 1994.

[59] Willem, R. A.: Design and Science. Design Studies, Vol. 11, No. 1, 1990, p. $43-47$

[60] Yoshikawa, H.: General Design Theory as a Formal Theory of Design. In Intelligent CAD, Vol. 1, ed. by Yoshikawa, H., Gossard, D., Amsterdam: North Holland, 1987, p. $51-61$.

[61] Yoshikawa, H.: Design Philosophy: The State of the Art. Annals of the CIRP, Vol. 38, No. 2, 1989, p. 579-586.

[62] Zeid, I.: CAD/CAM: Theory and Practice. New York: McGraw-Hill, Inc., 1991.

[63] Ziman, J.: Real Science. Cambridge: Cambridge University Press, 2000.

Imre Horváth

e-mail: i.horvath@io.tudelft.nl

Faculty of Industrial Design Engineering

Delft University of Technology

Landbergstraat 15

2628 CE, Delft, The Netherlands 